\title{
The contrastive and syntax analyses in the Thai and Malay languages
}

\begin{abstract}
This research is to decide the contrastive and difference aspects of syntax between the Malay language as the first language and the Thai language as the foreign language among the students in higher learning at public institutions in Malaysia. Both of these aspects is one of the factors that influenced the process of learning the Thai language among the students. A student is always making errors in oral and writing activities in the Thai language class. Hence, the objectives of this research are to identify the equation and differences in syntax aspect between the Thai and the Malay language, to identify types and the reasons of errors in learning the Thai language between students at the University Putra Malaysia (UPM) and University Kebangsaan Malaysia (UKM), and to submit the proposal, and the learning approaches to increase the control of the Thai language as the foreign language in Malaysia. To reach the objectives of this research, the researcher uses the theory of contrastive and error analysis. The samples of the research consisted of 100 students who have learned the Thai language from level one until level three from two chosen institutions.
\end{abstract}

Keyword: contrastive and syntax analyses 